\title{
SANGGIT CATUR LAKON KALABENDU SUSUNAN SUMANTO SAJIAN MANTEB SOEDHARSONO
}

\author{
Tri Wahyoe Widodo \\ Program Pascasarjana \\ Institut Seni Indonesia Surakarta \\ JI. Ki Hadjar Dewantara No. 19 Kentingan, Jebres, Surakarta, 57126
}

\begin{abstract}
ABSTRAK
Tujuan penelitian ini untuk mendeskripsi dan memahami struktur dramatik, sanggit catur, dan nilai-nilai dalam lakon Kalabendu susunan Sumanto sajian Manteb Soedharsono. Permasalahan yang dikaji adalah: (1) bagaimana struktur dramatik lakon Kalabendu susunan Sumanto sajian Manteb Soedharsono? (2) bagaimana sanggit dan garap catur lakon Kalabendu susunan Sumanto sajian Manteb Soedharsono?, dan (3) bagaimana nilainilai yang disampaikan dalam lakon Kalabendu susunan Sumanto sajian Manteb Soedharsono? Bahan penelitian dikumpulkan melalui studi pustaka, wawancara, dan pengamatan langsung dan tidak langsung pada pertunjukan lakon Kalabendu susunan Sumanto sajian Manteb Soedharsono. Dalam penelitian ini digunakan analisis struktur dramatik, sanggit, dan garap catur dengan menggunakan metode deskriptif interpretatif. Hasil penelitian menunjukkan bahwa: (1) lakon Kalabendu susunan Sumanto sajian Manteb Soedharsono ini sebenarnya merupakan petikan adegan-adegan penting dari beberapa lakon tradisi yaitu : lakon Pamuksa, lakon Bale Sigala-gala, lakon Bratayuda, dan lakon Pendhawa Boyong. Tahapan-tahapan dramatik dalam lakon Kalabendu adalah: exposition, inciting-action, conflication, crisis, climax, resolution, dan conclusion. (2) Sanggit catur lakon Kalabendu susunan Sumanto terdapat sanggit janturan (janturan jejer, janturan adegan, dan janturan peristiwa), sanggit pocapan (pocapan situasi, pocapan peristiwa, pocapan mandiri, dan pocapan peralihan), serta sanggit ginem (ginem blangkon, ginem baku, ginem isen-isen, dan ginem banyol). Garap catur lakon Kalabendu sajian Manteb Soedharsono terdapat garap janturan (janturan adegan), garap pocapan (pocapan peristiwa), dan garap ginem (ginem blangkon).(3) nilai-nilai yang disampaikan dalam lakon Kalabendu susunan Sumanto sajian Manteb Soedharsono adalah: nilai rendah-hati, nilai kesederhanaan, nilai tanggung-jawab, nilai kejujuran, nilai kebenaran, nilai persatuan, nilai balas budi, nilai ketuhanan, nilai ngundhuh wohing pakarti (hukum karma), nilai pendidikan, dan nilai keteguhan hati.
\end{abstract}

Kata kunci: struktur dramatik, sanggit catur, nilai-nilai, lakon Kalabendu.

\begin{abstract}
The purpose of this study is to describe and understand the dramatic structure, sanggit, catur and values in lakon Kalabendu of Sumanto's composition presented by Manteb Soedharsono. The problems studied are: (1) how the dramatic structure of Kalabendu by Sumanto presented by Manteb Soedharsono? (2) how is sanggit and garap catur of Kalabendu by Sumanto presented by Manteb Soedharsono ?, and (3) how the values presented in the Kalabendu by Sumanto presented by Manteb Soedharsono? Research materials were collected through literary studies, interviews, and direct as well as indirect observations of the Kalabendu performance of the Sumanto statue of Manteb Soedharsono. This study uses the analysis of dramatic structure, sanggit, and garap catur. This study uses interpretative descriptive method. The results of the research show that: (1) Lakon Kalabendu of Sumanto's composition presented by Manteb Soedharsono is actually an excerpt of important scenes from several traditional lakon: Pamuksa, Bale Sigala-gala, Bratayuda, and Boyong pendhawa. Dramatic stages in Kalabendu are: exposition, inciting-action, conflication, crisis, climax, resolution, and conclusion. (2) The sanggit catur of Kalabendu arranged by Sumanto is janturan (janturan jejer, janturan adegan, and janturan events), sanggit of pocapan (pocapan of situation, pocapan of event, pocapan of mandiri, and pocapan of transit), and sanggit of ginem (ginem blangkon, ginem baku, ginem isen-isen, and ginem banyol). Garap catur of Kalabendu by Manteb Soedharsono include janturan (janturan adegan), pocapan (pocapan adegan), and ginem (ginem blangkon). (3) The values presented in lakon Kalabendu composed by Sumanto presented by Manteb Soedharsono covering the values of: humble, simplicity, responsibility, honesty, truth, unity, relationship, divinity, karma, education, and steadiness.
\end{abstract}

Keywords: dramatic structure, sanggit catur, values, lakon Kalabendu 


\section{GEEAR Jumal Sai isudya}

\section{A. Pengantar}

Sejak sekitar tahun 1976, dunia pedalangan mengalami perubahan cukup mendasar. Perubahan itu adalah munculnya spesialis-spesialis tertentu seperti penyaji, penyusun naskah, penyusun karawitan dan penyusun sabet (Sumanto dalam Murtiyoso dkk, 2007:48). Keadaan tersebut membuat peneliti tertarik untuk mengkaji sebuah pertunjukan wayang kulit hasil dari kerjasama penyusun lakon dan penyaji lakon, khususnya pada wilayah sanggit catur. Penelitian ini merupakan sebuah studi kasus pada lakon Kalabendu susunan Sumanto sajian Manteb Soedharsono yang disajikan pada tanggal 25 Maret 2001 di Taman Budaya Jawa Tengah Surakarta. Lakon Kalabendu tersebut sebenarnya merupakan bagian dari acara syukuran Gunawan Soemodiningrat yang diangkat sebagai Guru Besar di Fakultas Ekonomi Universitas Gadjah Mada dan pengukuhannya sebagai Dewan Penyantun Sekolah Tinggi Seni Indonesia Surakarta. Dalam acara syukuran tersebut dipergelarkan pertunjukan wayang yang mempunyai misi moral yang ditujukan kepada para pemimpin bangsa Indonesia dengan lakon Kalabendu. Kalabendu artinya bencana, diambil sebagai judul lakon dengan maksud untuk memperingatkan para pemimpin bangsa Indonesia yang sedang berseteru dan membuat panasnya suhu politik, sehingga mengakibatkan terpuruknya sendi-sendi kehidupan berbangsa dan bernegara.

Masalah-masalah yang muncul dalam pengamatan lakon Kalabendu susunan Sumanto sajian Manteb Soedharsono ini antara lain: struktur dramatik, sanggit dan garap catur, serta pesan-pesan yang berupa nilai moral yang ada di dalamnya, baik disajikan secara tersurat dan tersirat dalam setiap adegan. Oleh karena itu naskah Kalabendu ini menarik untuk dikaji. Agar pembahasan dapat efektif dan terarah maka perumusan masalahnya diajukan sebagai berikut, (1) bagaimana struktur dramatik lakon Kalabendu susunan Sumanto sajian Manteb Soedharsono? (2) bagaimana sanggit dan garap catur lakon Kalabendu susunan Sumanto sajian Manteb Soedharsono?, dan (3) bagaimana nilai-nilai yang disampaikan dalam lakon Kalabendu susunan Sumanto sajian Manteb Soedharsono?

\section{B. Struktur dramatik lakon Kalabendu susunan Sumanto sajian Manteb Soedharsono}

Struktur dramatik secara definitif diartikan sebagai kesatuan peristiwa yang terdiri dari bagian- bagian yang memuat unsur-unsur plot (alur cerita). Rangkaian ini terstruktur dan saling memelihara kesinambungan cerita dari awal sampai akhir. Tujuannya untuk menyalurkan ide cerita dari seniman kepada penonton dengan melibatkan emosi penonton dalam ceritanya (Saptaria, 2006:25). Untuk itu, dibahas struktur dramatik lakon Kalabendu susunan Sumanto sajian Manteb Soedharsono dengan menggunakan konsep struktur dramatik Bretolt Bretch sebagai berikut.

a. Expotition: pembukaan dari sebuah cerita yang memberikan penjelasan dan keterangan mengenai tokoh-tokoh cerita, masalah-masalah yang sedang dilakoni, tempat dan waktu ketika cerita ini berlangsung.

b. Inciting-action: sebuah peristiwa atau tindakan yang dilakukan seorang tokoh yang membangun penanjakan aksi menuju konflik.

c. Conflication: penggawatan yang merupakan kelanjutan dan peningkatan dari expotition dan inciting-action. Pada bagian ini salah seorang tokoh cerita mulai mengambil prakarsa untuk mencapai tujuan tertentu. Walaupun dibayang-bayangi oleh ketidakpastian, keteguhan sikap sang tokoh ini tidak menyurutkan niatnya. Dengan demikian, tumbuhlah kegawatan-kegawatan yang saling bertubrukan dengan tokoh lainnya.

d. Crisis: berkembangnya suatu tindakan menuju klimaks. Artinya benih-benih kegentingan konflik antar tokoh mengemuka menjelang klimaks.

e. Climax: merupakan tahapan peristiwa dramatik yang telah dibangun oleh konflikasi. Tahapan ini melibatkan pihak-pihak yang berlawanan untuk saling berhadapan dalam situasi puncak pertentangan. Bentrokan tersebut mempertaruhkan nasib para tokoh, dan juga menentukan bagi mereka untuk tetap eksis atau tersingkir.

f. Resolution: adalah bagian struktur dramatik yang mempertemukan masalah-masalah yang diusung oleh para tokoh dengan tujuan untuk mendapat solusi atau pemecahan.

g. Conclusion: adalah tahapan akhir dari jalinan struktur dramatik, dimana nasib para tokoh mendapat kepastian. Bisa juga berupa pesan moral dari peristiwa-peristiwa yang terjadi (Saptaria, 2006:26-27).

Namun demikian, unsur-unsur tersebut di atas tidak mutlak harus ada melainkan bergantung dari permasalahan dan tujuan lakon itu sendiri. Untuk membicarakan struktur dramatik lakon Kalabendu susunan Sumanto sajian Manteb Soedharsono 
terlebih dahulu akan dipaparkan Balungan lakon. Hal ini penting karena untuk melihat struktur dramatik harus mengetahui lebih dulu alur ceritanya (plot).

\section{Balungan Lakon Kalabendu}

Balungan lakon atau kerangka garis besar lakon adalah urutan dan peristiwa yang terjadi dalam seluruh lakon (Sarwanto, 2008: 173). Balungan lakon atau urutan adegan lengkap dalam lakon Kalabendu susunan Sumanto sajian Manteb Soedharsono seperti tertera berikut ini.

Bagian pathet nem terdiri atas adegan:

a. Adegan pertempuran Prabu Pandhu melawan Prabu Tremboko hingga meninggalnya Prabu Pandhu dan Prabu Tremboko.

b. Adegan Sengkuni dan Gendari.

c. Adegan jejer Hastina hingga bedholan.

d. Adegan Limbukan.

e. Adegan Paseban njaba dilanjutkan budhalan

f. Adegan Jejer kedua (Pagombakan)

g. Adegan Jejer ketiga (Pura Waranawata)

h. Adegan Perang gagal (Bratasena melawan Purucana)

Bagian pathet sanga terdiri atas adegan:

a. Adegan Sengkuni dan Gendari

b. Adegan Jejer Hastina (wisudhan Kurupati)

c. Adegan Baratayuda berisi: Bisma Gugur, Abimanyu Ranjab, Gathutkaca Gugur (suluhan), dan Dorna Gugur.

Bagian pathet manyura terdiri atas adegan:

a. Adegan Ianjutan Baratayuda yang berisi: Dursasana Gugur (Jambakan), Karna Gugur, Salya Gugur, Sengkuni Gugur, dan Duryudana Gugur.

b. Adegan Hastina, Destarastra dan Gendari hingga kedatangan Pandawa.

c. Adegan Destarastra dan Gendari, tanceb kayon

Dari penjelasan diatas dapat diketahui bahwa lakon Kalabendu masih mengggunakan tiga pathet, yaitu pathet nem, pathet sanga, dan pathet manyura. Selain itu lakon Kalabendu susunan Sumanto sajian Manteb Soedharsono ini sebenarnya merupakan petikan adegan-adegan penting dari beberapa lakon tradisi yaitu :

a. Iakon Pamuksa (pertempuran antara Pandhu dan Tremboko),

b. lakon Bale Sigala-gala (usaha Kurawa untuk membunuh Pandawa dengan cara membuat perangkap untuk Pandawa lalu membakar Pandawa hidup-hidup di dalam Bale Sigala-gala), c. lakon Bratayuda (cerita peperangan Pandawa melawan Kurawa yang berakhir dengan kemenangan Pandawa), dan

d. dan lakon Pendhawa Boyong (cerita setelah Baratayuda berakhir dan Pandawa menempati kerajaan Hastina).

\section{Tahapan Struktur Dramatik}

a. Exposition

Pembukaan cerita mengenai Kalabendu ini dimulai dari adegan peperangan antara Prabu Pandhu melawan Prabu Tremboko yang berakhir dengan kematian Prabu Tremboko dan terluka parahnya Prabu Pandhu. Di saat-saat terakhir menjelang kematiannya, Prabu Pandhu menitipkan kerajaan Hastina dan para putra-putranya Pandawa kepada Destarastra, dengan pesan bila nanti para Pandawa telah dewasa negara Hastina harus diserahkan kepada para Pandawa.

b. Inciting-action

Tahap inciting-action pada lakon Kalabendu ini dimulai dari lima tahun semenjak kematian Pandhu. Desakan dari Bisma untuk melantik Pandawa menjadi raja justru memunculkan peluang bagi Sengkuni untuk menghabisi para Pandawa sebelum upacara pelantikan Pandawa menjadi Raja Hastina. Sengkuni berencana akan membakar Pandawa hidup-hidup di dalam Pura Waranawata.

c. Conflication

Cerita Kalabendu berkembang menuju tahap berikutnya yaitu tahap conflication, dalam tahap ini sudah dimunculkan kesan bahwa Pandawa sebenarnya meragukan niat baik Destarastra untuk melantik Pandawa menjadi raja. Namun Kunti mengingatkan para Pandawa bahwa niat baik Destarastra harus diterima dengan baik pula. Akhirnya para Pandawa bersedia untuk tinggal di Pura Waranawata. Setelah lewat waktu tengah malam, orang suruhan Sengkuni yang bernama Purucana membakar Pura Waranawata. Berkat kewaspadaan Bratasena dan Premadi, para Pandawa dan Kunti berhasil meloloskan diri dari kobaran api. Pandawa kemudian meninggalkan Pura Waranawata.

d. Crisis

Cerita terus berkembang menuju tahap crisis, artinya benih-benih kegentingan konflik semakin memuncak. Peristiwa yang diceritakan dalam tahap ini adalah saat Sengkuni dan Gendari mengusulkan kepada Destarastra dan Bisma agar segera menobatkan Kurupati sebagai Raja Hastina. 


\section{GE $[A R$ Jurnal Seni Budaya}

Adegan ini adalah tahap crisis, karena dalam adegan ini terdapat peristiwa yang bertolak belakang dengan tahap exposition, peristiwa tersebut adalah tindakan Destarastra, terlepas dari apapun alasannya, telah secara nyata tidak melaksanakan amanat Pandu sebelum meninggal.

\section{e. Climax}

Beberapa tahun kemudian, pecah perang besar antara Pandawa dan Kurawa yang dikenal dengan nama Baratayuda Jayabinangun. Tahap ini merupakan tahap climax, karena dalam tahap ini dua kubu yang berlawanan yaitu Pandawa dan Kurawa saling berhadapan dalam situasi puncak pertentangan, di mana pertentangan tersebut mempertaruhkan nasib kedua kubu tersebut, dan juga menentukan bagi mereka untuk tetap eksis atau tersingkir.

f. Resolution

Pada tahap resolution ini diceritakan mengenai kedatangan para Pandawa ke Hastina. Kedatangan para Pandawa tersebut disambut oleh Destarastra dan Gendari. Dalam pertemuan tersebut Werkudara menyindir Destarastra dengan kata-kata yang kasar karena Destarastra dianggap tidak berhasil mendidik anak, bahkan Destarastra selalu melindungi perbuatan para Kurawa yang tidak terpuji.

g. Conclusion

Tahap selanjutnya adalah adegan di mana Destarastra dan Gendari meratapi nasib mereka yang sengsara. Namun dalam kesengsaraan tersebut mereka berdua tidak bisa merasakan kebersamaan. Bahkan keduanya justru bertengkar saling menyalahkan.

\section{Sanggit dan Garap Catur lakon Kalabendu susunan Sumanto sajian Manteb Soedharsono}

Analisis sanggit dan garap catur lakon Kalabendu susunan Sumanto sajian Manteb Soedharsono dalam bentuk pakeliran semalam. Sanggit merupakan bagian terpenting dari garap, yang berfungsi mengarahkan penggarapan unsur-unsur pakeliran. Adapun garap merupakan implementasi sanggit (Nugroho, 2012:425-428). Pada kasus ini, wilayah sanggit catur meliputi unsur catur (janturan, pocapan, dan ginem) dalam lakon Kalabendu susunan Sumanto, sedangkan wilayah garap catur meliputi unsur catur (janturan, pocapan, dan ginem) dalam lakon Kalabendu sajian Manteb Soedharsono.

\section{Sanggit Catur}

Pembahasan mengenai sanggit catur akan dikelompokkan menjadi tiga hal: sanggit janturan, sanggit pocapan, dan sanggit ginem.

a. Sanggit janturan

Janturan dapat dikelompokkan menjadi tiga jenis: janturan yang digunakan untuk menyertai sebuah jejer (disebut janturan jejer), janturan yang digunakan untuk menyertai sebuah adegan (disebut janturan adegan), dan janturan yang digunakan untuk melukiskan peristiwa yang sedang terjadi dalam pakeliran (disebut janturan peristiwa) (Nugroho,2012:429).

\section{a.1. Janturan jejer}

Janturan jejer dalam lakon Kalabendu susunan Sumanto terdapat pada janturan Negara Hastina berikut.

Sinawung panglingga murda mring purbaning Hyang Mahajati, jatine kang murweng kawi kawilet ing kalenglengan. Leng-leng kalangkung kumedah medhar warana winadi. Wadi jantraning ngaurip. Rinipta jro pangrumpaka, pikolehe mamrih dadya sarana panimbang mawas laku lelakoning nagri.

(Dengan menyembah kekuasaan Tuhan, sejatinya si pencerita (dalang) dirundung kesedihan. Sedih yang teramat sangat. Sehingga harus memaparkan sebuah rahasia. Rahasia perjalanan hidup. Yang digubah dalam perumpamaan, bertujuan supaya menjadi sarana pertimbangan dalam melihat keadaan negara.)

\section{a.2. Janturan adegan}

Janturan adegan dalam lakon Kalabendu susunan Sumanto di antaranya terdapat pada adegan Destarastra dan Gendari. Kutipan dari janturan adegan tersebut adalah sebagai berikut.

Kedhaton Ngastina kang duk ing nguni endahe kondhang ing jagad tanpa timbang sakala kumel kucem kabyatan rudatin. Tetuwuhan samya nggagrag alum kasatan warih, kembang-kembang koncadan ganda arum sataemah nglayung layu mbalasah tiba ing lemah.

(Istana Hastina yang di masa lampau keindahannya terkenal tanpa tanding di dunia 
seketika suram menanggung kesusahan. Tanaman layu kekurangan air, bunga-bunga kehilangan keharuman sehingga layu gugur di tanah.)

\section{a.3. Janturan peristiwa}

Janturan peristiwa dalam lakon Kalabendu susunan Sumanto dapat diamati di antaranya dalam adegan prolog. Berikut ini adalah janturan peristiwa tersebut.

Mangkana Prabu Pandhudewanata magut yuda nempuh Prabu Tremboko. Kekalihira tuhu sura sudibya. Tangguh tanggon wudhu bobot pilih tandhing. Sigra samya nguras kasekten, ngetog daya linuwih.

(Saat itu Prabu Pandudewanata bertempur melawan Prabu Tremboko. Keduanya benarbenar berani dan sakti. Sama-sama tangguh dan seimbang kehebatannya. Mereka segera menguras kemampuan, mengeluarkan daya kesaktian.)

b. Sanggit pocapan

Pocapan dapat dikelompokkan menjadi empat jenis: pocapan yang digunakan untuk menggambarkan situasi adegan (disebut pocapan situasi), pocapan yang digunakan untuk menggambarkan peristiwa yang terjadi dalam pakeliran (disebut pocapan peristiwa), dan pocapan yang digunakan untuk menyertai bagian dari suatu adegan dengan porsi mendominasi bagian itu (disebut pocapan mandiri), mengalihkan perhatian dari adegan satu ke adegan berikutnya (disebut pocapan peralihan) (Nugroho,2012:430).

\section{b.1. Pocapan situasi}

Pocapan situasi dalam lakon Kalabendu susunan Sumanto dapat diamati di antaranya dalam adegan kedatangan Pandawa di Hastina. Pocapan situasi tersebut adalah sebagai berikut.

Susah sengit ngigit-igit kaworan duka yayah sinipi nenggih Adipati Dhestarastra. Panduking duka namung dhateng Werkudara kang tansah blejeti alane ngeler wirange,

(Susah sedih teramat sangat bercampur amarah yang membara sang Adipati Destarastra. Tujuan amarahnya hanya kepada Werkudara yang selalu menelanjangi keburukannya dan membuka aibnya.)

\section{b.2. Pocapan peristiwa}

Pocapan peristiwa dalam lakon Kalabendu susunan Sumanto dapat diamati di antaranya dalam adegan prolog. Pocapan peristiwa tersebut adalah sebagai berikut.

Wuru unggul mendem menang yata Prabu Pandhudewayana. Petak macia-cia kaya-kaya jagad ora ana kang madhani kasektene. Sarwi sesongaran ngideri Tremboko njrebabah ndhepani lemah. Awit kabrananging gambira, satemah ilang parayitnaning batin, tan kanyana, tumapaking pada ngidak Kalanadhah, Prabu Pandhu rubuh padha sakala.

(Mabuk kemenangan Prabu Pandudewanata. Berteriak-teriak seakan-akan di jagad tidak ada yang bisa menyamai kesaktiannya. Dengan congkaknya mengitari Tremboko yang sudah berkalang tanah. Karena terbakar perasaan, menjadi hilang kewaspadaannya, kaki menginjak Kalanadah. Prabu Pandu roboh seketika.)

\section{b.3. Pocapan mandiri}

Pocapan mandiri dalam lakon Kalabendu susunan Sumanto dapat diamati di antaranya dalam adegan gara-gara. Berikut ini pocapan gara-gara tersebut.

Gara-gara. Gara-gara gora reh kagiri-giri, dumadi saka dayaning ratu kang cidra ing janji. Panguwasa kang nerak wewaler mungkur saka bebener. Pangarsaning praja padha rebut bener lelandhesan ati keblinger. Kang sinung wenang padha tumindak sawenangwenang. Budi luhur wus siningkur, tata krama wus sirna, kautaman kari aran. Pitutur becik disirik, piwulang suci mung kandheg ana lathi. Tepa tuladha ora ana, budi pekerti wis mati.

(Gara-gara. Gara-gara yang besar dan menakutkan, terjadi karena raja yang ingkar janji. Pejabat kerajaan saling mengaku paling benar berdasarkan hati yang salah. Yang mempunyai kekuasaan menggunakan kekuasaannya dengan dengan sewenangwenang. Budi luhur sudah ditinggalkan, tatakrama sudah sirna, kebaikan hanya tinggal nama. Nasehat baik ditolak, ajaran suci hanya tinggal dibibir saja. Teladan tidak ada, budi pekerti sudah mati.) 


\section{GE[AR surmal sair iublya}

\section{b.4. Pocapan peralihan}

Pocapan peralihan dalam lakon Kalabendu susunan Sumanto dapat diamati di antaranya dalam adegan Pura Waranawata. Berikut ini adalah pocapan peralihan tersebut.

Kocap, gancanging carita, Pandhawa wus prapta Pura Waranawata, pinapag Adipati Dhestarastra miwah Kurawa, katon raket sumanak tanduke. Nulya samya aglar bujana andrawina, dhedhaharan makendhungkendhung, inuman mawarni-warni, parandene Pandhawa datan kersa dhahar tanapi nginum.

(Syahdan, ringkas cerita, Pandawa sudah sampai di Pura Waranawata, disambut Adipati Destarastra serta Kurawa, terlihat akrab dan ramah tingkahnya. Lalu menggelar pesta makan. Makanan beraneka macam, minuman bermacam-macam, namun Pandawa tidak mau makan maupun minum.)

\section{Sanggit ginem}

Ginem dalam pakeliran mempunyai fungsi untuk mengungkapkan permasalahan dalam lakon lewat wacana tokoh sesuai dengan kedudukannya dalam lakon. Selain itu ginem juga mengungkapkan perwatakan tokoh-tokoh sesuai dengan karakter masing-masing tokoh. Ginem dapat dibedakan menjadi lima macam, yakni ginem blangkon, ginem baku, ginem isen-isen, ginem sampiran dan ginem banyol. Ginem blangkon adalah percakapan wayang yang telah terpola sedemikian rupa sehingga dalang tinggal menerapkan dalam pakeliran sesuai dengan kondisi dan situasi adegan. Ginem baku adalah percakapan wayang yang berkaitan langsung dengan permasalahan tokoh dalam sebuah peristiwa lakon. Ginem isenisen adalah percakapan wayang yang masih berkaitan dengan permasalahan tokoh tetapi telah mengalami variasi, biasanya dikaitkan dengan masalah-masalah humanistik. Ginem sampiran adalah percakapan wayang tentang pesan-pesan tertentu di luar permasalahan tokoh dalam peristiwa lakon. Adapun ginem banyol adalah percakapan wayang untuk membuat tertawa penonton. Ginem banyol ini ada yang terkait dengan alur cerita (disebut banyol gawan lakon) dan ada yang terlepas sama sekali dengan lakon (disebut banyol medal saking kelir) (Nugroho,2012:431).

c.1. Ginem blangkon
Ginem blangkon dalam lakon Kalabendu susunan Sumanto dapat diamati di antaranya dalam idiolek tokoh Drona dalam ginem berikut: Durna:Lole lole kenthos mondos waloh gembol, jebebeg si monyor-monyor, Kakang Adipati sak menika gampil kesupen, sauger dipun emutaken, kanthi cara dikruwes wentise, sakala byar lagi terus eling.

(Lole lole kenthos mondos waloh gembol, jebebeg si monyor-monyor, Kakanda Adipati sekarang jadi gampang lupa, tapi kalau diingatkan, dengan cara dicubit pahanya, seketika langsung ingat.)

Kalimat "lole lole kenthos mondos waloh gembol, jebebeg si monyor-monyor" merupakan idiolek yang dalam dunia pedalangan merupakan ciri khas dari tokoh Drona. Kalimat "lole lole kenthos mondos waloh gembol, jebebeg si monyor-monyor" itu sendiri walaupun memakai kata-kata dalam bahasa Jawa, namun sangat sulit untuk diartikan.

\section{c.2. Ginem baku}

Ginem baku dalam lakon Kalabendu susunan Sumanto dapat diamati di antaranya dalam adegan Pagombakan.

Kunthi : Kulup, anak-anakku Pandhawa, Wakira Dipati katone wis mulung atine.

(Nak, anak-anakku Pandawa, Uwakmu Dipati sepertinya sudah rela hatinya.)

Puntadewa: Kanjeng Ibu, kaluhuran pangandika paduka, menapa sampun titi wanci Pandhawa kedah wangsul mukti.

(Ibu, betul perkataan ibu, apa sudah saatnya Pandawa harus kembali hidup mulia)

Sena : Nadyan mengkono, becik aja gampang percaya, kaya ora ngerti watake Wa Dhestarastra sak anake. Aja-aja anggone melung mung kanggo nutupi alane awit wedi karo Eyang Bisma. 
(Walau begitu, sebaiknya jangan mudah percaya, seperti tidak tahu wataknya Uwak Destarastra dan anak-anaknya. Jangan-jangan kerelaannya hanya untuk menutupi kejahatannya karena takut pada Eyang Bisma.)

\section{c.3. Ginem isen-isen}

Ginem isen-isen dalam lakon Kalabendu susunan Sumanto dapat diamati di antaranya dalam adegan Pagombakan.

Yamawidura: Kakang Mbok Ratu, nyuwun pangapunten menawi ingkang rayi nggempil anggenipun nedheng sami rerembagan.

(Kakanda Ratu, mohon maaf kalau adinda mengganggu yang sedang berbicara.)

Kunthi : Yayi Widura ora dadi baya pengapa, iku mau putraputramu padha matur lamun rumangsa tentrem mapan Pagombakan. Mula yayi, pun Kakang ngaturake panuwun, dene Si Adhi gelem ngukup para Pandhawa.

(Dinda Widura tidak apaapa, ini tadi putra-putramu mengatakan bahwa merasa tenteram tinggal di Pagombakan. Karena itu dinda, aku mengucapkan terimakasih, karena Dinda bersedia melindungi para Pandawa.)

\section{c.4. Ginem banyol}

Ginem banyol dalam lakon Kalabendu susunan Sumanto dapat diamati di antaranya dalam adegan jejer Hastina.

Durna : Lole lole kenthos mondos waloh gembol, jebebeg si monyor-monyor, Kakang Adipati sak menika gampil kesupen, sauger dipun emutaken, kanthi cara dikruwes wentise, sakala byar lagi terus eling.

(Lole lole kenthos mondos waloh gembol, jebebeg si monyor-monyor, Kakanda Adipati sekarang jadi gampang lupa, tapi kalau diingatkan, dengan cara dicubit pahanya.. seketika langsung ingat.)

Ginem tersebut kalau diamati sebenarnya merupakan sebuah sindiran tentang sekelompok orang pembohong yang kurang kompak dalam melakukan aksi kebohongannya. Namun sindiran itu dikemas menjadi sebuah humor segar yang tetap tidak keluar dari alur cerita yang disajikan. Ginem banyol ini termasuk dalam jenis ginem banyol yang terkait dengan alur cerita (disebut banyol gawan lakon).

2. Garap Catur

a. Garap janturan

Manteb Soedharsono dalam menggarap lakon Kalabendu susunan Sumanto, secara sengaja memang tidak selalu menyajikan sama persis dengan naskah yang disusun oleh Sumanto. Manteb Soedharsono menambahkan janturan pada suatu adegan, di mana dalam naskah susunan Sumanto janturan tersebut tidak ada. Janturan yang ditambahkan oleh Manteb Soedharsono terdapat pada adegan Pagombakan. Berikut ini adalah kutipan janturan yang ditambahkan oleh Manteb Soedharsono tersebut.

Lah punika ta warnanipun kasatriyan Pagombakan kitha alit tlatah negari Ngastina. Pranyata kang mapan ing kono janma kang narima ing pandum, tan asanes kejawi Dewi Kunthi Talibrata, kaadhep para Pandhawa. Sang Puntadewa, Harya Sena, Dyan Premadi, Nakula lan Sadewa. Datan kantun repat Panakawan ingkang tut wuri handayani, Ki Lurah Semar, Nala Gareng, Petruk, miwah Bagong.

(Inilah wujudnya kasatriyan Pagombakan, kota kecil wilayah Negara Hastina. Ternyata yang berdiam di situ adalah insan yang sederhana, tiada lain Dewi Kunti Talibrata, dengan para Pandawa. Sang Puntadewa, Harya Sena, Dyan Premadi, Nakula dan Sadewa. Tidak ketinggalan para Panakawan yang selalu mengikuti, Ki Lurah Semar, Nala Gareng, Petruk, serta Bagong.)

Garap janturan Manteb Soedharsono ini dilihat dari jenisnya termasuk di dalam kategori janturan adegan. 


\section{GEEAR Jumal Scri Bublya}

b. Garap pocapan

Manteb Soedharsono juga melakukan perubahan pocapan pada adegan Pandhu terkena keris Tremboko. Dalam naskah asli susunan Sumanto, pocapan adegan tersebut adalah sebagai berikut.

Wuru unggul mendem menang yata Prabu Pandhudewanata. Petak macia-cia kaya-kaya jagad ora ana kang madhani kasektene. Sarwi sesongaran ngideri Tremboko njrebabah ndhepani lemah. Awit kabrananging gambira, satemah ilang parayitnaning batin, tan kanyana, tumapaking pada ngidak Kalanadhah. Prabu Pandhu rubuh padha sakala.

(Mabuk kemenangan Prabu Pandhudewanata. Berteriak-teriak seakanakan di jagad tidak ada yang bisa menyamai kesaktiannya. Dengan congkaknya mengitari Tremboko yang sudah berkalang tanah. Karena terbakar perasaan, menjadi hilang kewaspadaannya, kaki menginjak Kalanadhah. Prabu Pandhu roboh seketika.)

Dalam pocapan tersebut diceritakan bahwa Pandhu lengah hingga tak sengaja menginjak keris Tremboko yang bernama Kyai Kalanadah. Sedangkan pocapaan yang sudah dirubah oleh Manteb Soedharsono adalah sebagai berikut.

Wuru unggul mendem menang yata Prabu Pandhudewanata. Petak macia-cia kaya-kaya jagad ora ana kang madhani kasektene. Sarwi sesongaran ngideri Tremboko njrebabah ndhepani lemah. Awit kabrananging gambira, satemah ilang parayitnaning batin, tan kanyana, anyarengi pecat yitmane Prabu Tremboko, kaya ana daya linuwih ingkang njalari mencolot Kyai Kalanadhah tumanduk wentise Prabu Pandhu, rebah dadi royongan.

(Mabuk kemenangan Prabu Pandhudewanata. Berteriak-teriak seakan-akan di jagad tidak ada yang bisa menyamai kesaktiannya. Dengan congkaknya mengitari Tremboko yang sudah berkalang tanah. Karena terbakar perasaan, menjadi hilang kewaspadaannya, tanpa diduga, ada kekuatan hebat yang menyebabkan terlontarnya Kyai Kalanadah mengenai paha Prabu Pandhu, roboh seketika.)
Garap pocapan Manteb Soedharsono ini dilihat dari jenisnya termasuk di dalam kategori pocapan peristiwa.

c. Garap ginem

Pada adegan Pagombakan, Manteb Soedharsono juga menambahkan ginem yang tidak tertulis dalam naskah susunan Sumanto. Ginem tambahan Manteb Soedharsono adalah sebagai berikut.

Kunthi : Kadangku yayi, yayi Widura kanthi karaharjan praptanira yayi?

(Saudaraku, Adinda Widura, apakah kau datang dengan selamat?)

Yamawidura: Kawula nuwun inggih kakang mbok ratu. Awit saking berkah pangestu paduka kakangmbok ratu raharja pisowan kula, bekti kula katur kakangmbok.

(lya Ayunda Ratu. Berkat restu paduka Ayunda Ratu saya datang dengan selamat, terimalah hormatku ayunda.)

Kunthi : lya yayi, pangabektinira wis dak tampa.

(lya adinda, hormatmu sudah kuterima.)

Garap ginem Manteb Soedharsono ini dilihat dari jenisnya termasuk di dalam kategori ginem blangkon.

\section{Nilai-nilai Yang Disampaikan Dalam Pertunjukan Wayang Lakon Kalabendu Susunan Sumanto Sajian Manteb Soedharsono}

Nilai-nilai dalam pertunjukan wayang adalah sesuatu yang dianggap baik dan benar bagi manusia dan dapat dijadikan pedoman dan tuntunan hidup di dalam masyarakat (Sarwanto, 2008: 272). Nilai-nilai dalam wayang tersebut dapat disampaikan secara langsung maupun tidak langsung oleh dalang kepada penonton. Bisa secara tersurat (melok) maupun tersirat (medhang miring). Nilai-nilai yang disampaikan secara melok akan sangat mudah diterima oleh penonton, sedangkan nilai-nilai yang disampaikan secara medhang miring akan tidak selalu mudah untuk dimengerti karena membutuhkan penafsiran dari 
penonton. Untuk mempermudah dalam mengungkap nilai-nilai pada lakon Kalabendu tersebut, akan pernyataan Suratno dalam tulisannya, "Makna dan Fungsi Pertunjukan Wayang Kulit pada Upacara Ritual di Dukuh Logantung, Semin, Gunung Kidul", yang menyatakan bahwa:

.... wayang adalah salah satu sarana pembinaan budi pekerti agar para anggota masyarakat selalu taat terhadap norma sosial yang diyakini masyarakat. Dengan mencermati pesan-pesan yang disampaikan lewat adegan-adegan dalam pementasan wayang akan mendapatkan nilai keteladanan, misalnya sikap bermasyarakat yang baik, hormat-menghormati sesama makluk, sikap bergotong-royong, kepedulian terhadap sesama anggota masyarakat, dan sebagainya (Suratno, 2007:367).

Berdasarkan pernyataan Suratno di atas, penulis berpendapat bahwa nilai dalam wayang tersembunyi di balik pesan-pesan yang disampaikan oleh dalang. Oleh karena itu, untuk dapat mengungkap nilai-nilai dalam wayang, terlebih dahulu harus bisa mencermati pesan-pesan yang disampaikan oleh dalang lewat adegan-adegan dalam lakon wayang tersebut.

Untuk mengungkap nilai-nilai dalam lakon Kalabendu ini lebih lanjut akan dipaparkan: (1) pesanpesan yang terdapat pada adegan-adegan dalam lakon Kalabendu dan (2) nilai-nilai yang terkandung dalam pesan-pesan pada lakon Kalabendu.

\section{Pesan-pesan dalam Adegan Lakon Kalabendu}

Dalam memaparkan mengenai pesan-pesan yang terdapat pada lakon Kalabendu tersebut akan dibahas mengenai: (1) adegan prolog, (2) adegan Gendari dan Sengkuni, (3) adegan jejer pertama Hastina, (4) adegan Pagombakan, (5) adegan Baratayuda Jayabinangun, (5) adegan Hastina, dan (6) adegan Dhestarastra dan Gendari.

\section{a. Adegan Prolog}

Pada bab sebelumnya telah dikemukakan bahwa setelah berhasil menewaskan Tremboko, Pandhu tidak bisa menyembunyikan rasa bangganya sehingga muncullah rasa sombong di hati Pandhu. Kesombongan yang timbul mengakibatkan berkurangnya kewaspadaan Pandhu, sehingga tanpa sengaja Pandhu terkena senjata Tremboko yang bernama Keris Kalanadhah hingga mengakibatkan Pandhu terluka parah. Baru setelah terluka parah, Pandhu menyadari kesalahannya. Dalam adegan ini sebenarnya terkandung sebuah pesan mengenai "akibat buruk dari kesombongan".

\section{b. Adegan Gendari dan Sengkuni}

Sepeninggal Pandhu, Gendari dan Sengkuni berusaha memanfaatkan keadaan itu, dengan menyusun siasat agar kelak yang menggantikan posisi sebagai Raja Hastina bukanlah para Pandawa melainkan para Kurawa. Sengkuni berencana menggunakan posisinya sebagai Patih untuk memperlancar siasat tersebut, sedangkan Gendari akan menggunakan posisnya sebagai istri Raja Dhestarastra untuk mengalihkan perhatian Dhestarastra dari tugasnya sebagai raja agar Sengkuni dapat leluasa menjalankan siasat. Adegan tersebut tentunya bukanlah sebuah pesan untuk diteladani, namun ada hal menarik berupa pelajaran yang bisa dipetik dari ginem di atas, hal itu adalah bahwa tujuan Sengkuni dan Gendari adalah membuat Dhestarastra agar larut dalam menikmati kemewahan hidup, sehingga ia akan kehilangan kewaspadaan dan dengan mudah akan bisa dimanfaatkan oleh Gendari dan Sengkuni sebagai alat rencana jahat mereka. Bila diamati, adegan tersebut sebenarnya juga mengandung pesan, bahwa "orang yang terlalu larut dalam kenikmatan duniawi, akan mudah mendapatkan celaka".

\section{c. Adegan Jejer Pertama Hastina}

Janturan (narasi) pada jejer pertama Negara Hastina berisi tentang penggambaran keadaan Negara Hastina yang memprihatinkan. Keterpurukan Negara Hastina itu justru karena perbuatan para aparat pemerintahan dan pejabatnya, yang tidak teliti dalam menjalankan tugas dan hanya mempercayai laporan dari bawahannya, padahal laporan tersebut adalah laporan palsu yang tidak sesuai dengan kenyataan. Janturan tersebut mengandung pesan "pemimpin tidak boleh terlalu percaya dengan laporan bawahannya namun juga berkewajiban untuk turun langsung memeriksanya".

Pada adegan tersebut juga dikemukakan tindakan Bisma yang mempertanyakan tanggung jawab Dhestarastra dalam mengatur pemerintahan karena menurut Bisma Negara Hastina terlihat memprihatinkan. Pada saat itu Sengkuni memberi pembelaan pada Dhestarastra, menurut Sengkuni menurunnya wibawa Negara Hastina disebabkan kegagalan pemerintah di masa pemerintahan Prabu Pandhu. Pernyataan itu mendapat kecaman keras dari Bisma. Tindakan Sengkuni tersebut menurut Bisma adalah tindakan orang yang tidak mau bertanggung 


\section{GEEAR Jumal sai isulya}

jawab akan tugasnya. Pesan yang terkandung dalam ginem ini adalah "melemparkan tanggung jawab dengan menyalahkan orang lain adalah perbuatan yang tidak terpuji”.

Dhestarastra juga menyatakan pembelaan dirinya dengan mengungkapkan bahwa setiap usaha yang dilakukannya tidak pernah didukung bahkan selalu ditentang oleh pejabat-pejabat Negara Hastina yang lain. Yamawidura mengutarakan pendapat bahwa semua usaha yang dilakukan oleh Dhestarastra tidak mendapat dukungan dari pejabat pemerintahan Hastina karena mereka menganggap Dhestarastra tidak konsisten. Peraturan dan perintah yang diucapkan oleh Dhestarastra bertolak belakang dengan tindakan Dhestarastra sendiri. Pernyataan Yamawidura tersebut sebenarnya merupakan kritikan tajam pada kesalahan Dhestarastra. Pesan yang bisa ditangkap dari ginem di atas adalah "antara ucapan dan perbuatan haruslah selaras dan jangan sampai bertolak belakang".

Sementara itu Drona menanggapi keadaan Negara Hastina dengan pernyataan bahwa munculnya perselisihan itu karena di Hastina sudah tidak ada yang mampu menjadi teladan. Kebaikan hanya tinggal nama, budi luhur sudah hancur. Yang ada hanya ambisi hingga lupa diri, melanggar aturan kebaikan, menanam keburukan mengakibatkan kehancuran. Pernyataan Drona tersebut dapat disimpulkan sebagai sebuah pesan bahwa "sebuah negara yang di dalamnya tidak ada lagi kebaikan dan budi luhur, pasti akan menghadapi kehancuran".

Bisma kemudian mengingatkan Dhestarastra pada janjinya pada Pandhu untuk menyerahkan Negara Hastina kepada para Pandawa. Bisma berkata bahwa seorang raja itu kalau ingkar janji akan menerima dosa. Tidak hanya setelah meninggal namun juga di saat hidup. Terlebih lagi kalau sudah tidak menjabat, pasti akan dicemooh, di mana-mana menjadi bahan pembicaraan yang buruk. Peringatan Bisma pada Dhestarastra tersebut mengandung pesan bahwa "orang yang ingkar janji akan menerima akibatnya, tidak hanya berupa dosa ketika sudah meninggal, namun juga pada saat masih hidup".

\section{d. Adegan Limbukan}

Pada adegan limbukan disampaikan sebuah narasi berjudul orasi budaya dengan menggunakan bahasa Jawa yang dibacakan oleh dalang. Orasi tersebut berupa kritikan yang ditujukan kepada politikus-politikus pada masa itu yaitu Gus Dur (Abdurrahman Wahid), Mbak Mega (Megawati Soekarnoputri), Bang Amien (Amien Rais), dan Bung Akbar (Akbar Tandjung). Isi dari orasi tersebut adalah kritikan pada para politikus-politikus yang sedang bertikai tanpa memperdulikan nasib rakyat yang semakin lama semakin sengsara.

Berikut ini adalah kutipan orasi yang berupa kritikan pada Gus Dur.

Ingkang angka sepisan kagem Gus Dur. Kula kedah wantun angakeni menawi sekawit sanget-sanget anggen kula rumojong kepara kebak ing pangajeng-ajeng sadaya pambudidaya ingkang panjenengan tindakaken nggayuh masyarakat demokratis tamtu badhe kalaksanan nanging eman Gus, rinaos kok saya dangu malah saya tebih saking kasunyatan. Meh sadaya pakaryan panjenengan tansah tinampi mboten kaleresan. Kepara nuwuhaken daredah, kula sakanca menawi ningali laku jantraning pertunjukan nasional, saya suwe kok saya mbingungake.

(Yang pertama buat Gus Dur: Saya harus berani mengakui bahwa awalnya saya sangatsangat setuju bahkan berharap penuh semua usaha yang anda lakukan menuju masyarakat demokratis pasti akan terlaksana, tapi sayang Gus, rasanya kok semakin lama justru semakin jauh dari kenyataan. Hampir semua pekerjaan anda selalu tidak diterima [dianggap salah]. Bahkan menimbulkan perselisihan. Saya dan teman-teman kalau melihat jalannya "pertunjukan nasional" semakin lama kok semakin membingungkan)

Berikut ini adalah kutipan orasi yang berupa kritikan pada Amien Rais.

Ingkang angka kalih kagem Mas Amien Rais. Mugi-mugi midhanget atur kula. Wong pinter, wong kendel mboten kados panjenengan. Awal tahun 90-an nedhengipun Pak Harto prasasat idu geni, panjenengan wis wani mudhar gagasan nggih menika presiden $k i$ apike dua kali masa jabatan. Wah.. kancane Pak Harto nesu, kebakaran jenggot kabeh. Nanging panjenengan jalan terus. Hebat Mas Amien, Kula mboten ngertos menapa ingkang dipun ngendikakaken Pak Habibie putra siswanipun Pak Harto dhateng panjenengan. Nanging nyatanipun panjenengan dicopot dari Ketua Dewan Penasehat Ikatan Cendekiawan Muslim Indonesia utawi ICMI. Elokipun panjenengan tetap tidak perduli dan terus 
berkibar. Mas Amien, sakmenika Pak Harto sampun lengser, Pak Habibie sampun mandhap. Panjenengan sak kanca rowange nyundhul puyuh karo Gus Dur dadi presiden dan dengan air mata berlinang Mbak Mega tersingkir dengan efek Solo meh dadi karangabang.

(Yang kedua buat Mas Amien Rais. Semoga mendengarkan kata-kata saya. Orang pintar, orang berani, tidak ada yang seperti anda. Awal tahun 90-an ketika Pak Harto sangat berkuasa, anda sudah berani menyampaikan pendapat, yaitu presiden itu bagusnya dua kali masa jabatan. Wah, teman-teman Pak Harto marah, semua kebakaran jenggot, tetapi anda jalan terus. Hebat Mas Amien, Saya tidak mengerti apa yang dikatakan Pak Habibie murid Pak Harto pada anda. Tapi nyatanya anda dicopot dari Ketua Dewan Penasehat Ikatan Cendekiawan Muslim Indonesia atau ICMI. Hebatnya anda tetap tidak perduli, dan terus berkibar. Mas Amien, sekarang Pak Harto sudah turun, Pak Habibie sudah turun. Anda beserta teman-teman menjunjung Gus Dur menjadi presiden dan dengan air mata berlinang Mbak Mega tersingkir dengan efek Solo hampir menjadi lautan api.)

Berikut ini adalah kutipan orasi yang berupa kritikan pada Akbar Tandjung.

Ingkang kaping tiga kagem Bung Akbar Tandjung. Kula mboten maido, tidak mencela apa sebabnya setelah panjenengan menjadi ketua DPR RI pengawasan terhadap pemerintah dilaksanakan secara ketat dan keras. Ini terjadi antara lain, karena ketika panjenengan masih menjadi menteri atau nayakaning praja di jaman pak Harto, DPR rupanya agak rikuh mengawasi panjenengan. Disamping itu juga DPR juga tidak hanya mengawasi saja, pengawasan kan tidak hanya masalah Bulog dan kasus Sultan Brunai, masalah otonomi daerah misalnya. Masalah ini bila tidak diawasi dengan ketat pasti akan menimbulkan KKN-KKN baru di daerah dan kurang bejane akan menimbulkan pecahnya Negara Kesatuan Republik Indonesia. Coba Bung Akbar, apakah bung Akbar pernah mendengar yang dengan dalih otonomi daerah, seorang anggota DPRD dijatah tujuh ratus lima puluh ribu per bulan hanya untuk baca koran.
Ini terjadi di Makasar. Maca koran wae kok pitungatus seket ewu ki koran apa sing di waca?

(Yang ketiga untuk Bung Akbar Tandjung. Saya tidak menyalahkan, tidak mencela apa sebabnya setelah anda menjadi ketua DPR $\mathrm{RI}$ pengawasan terhadap pemerintah dilaksanakan secara ketat dan keras. Ini terjadi antara lain, karena ketika anda masih menjadi menteri atau pejabat negara di jaman Pak Harto, DPR rupanya agak canggung mengawasi anda. Disamping itu juga DPR juga tidak hanya mengawasi saja, pengawasan kan tidak hanya masalah Bulog dan kasus Sultan Brunai, masalah otonomi daerah misalnya. Masalah ini bila tidak diawasi dengan ketat pasti akan menimbulkan KKN-KKN baru di daerah dan akan menimbulkan pecahnya Negara Kesatuan Republik Indonesia. Coba Bung Akbar, apakah Bung Akbar pernah mendengar yang dengan dalih otonomi daerah, seorang anggota DPRD dijatah tujuh ratus lima puluh ribu per bulan hanya untuk baca koran. Ini terjadi di Makasar. Baca koran saja kok tujuh ratus lima puluh ribu itu koran apa yang dibaca?)

Berikut ini adalah kutipan orasi yang berupa kritikan pada Megawati.

Ingkang pungkasan kagem Mbak Mega. Para winasis, kalebet ingkang rama suwargi Bung Karno nate ngendika, "Janma Limpat Seprapat Tamat", kula ambali malih "Janma Limpat Seprapat Tamat".

(Yang terakhir untuk Mbak Mega. Para cendekiawan, termasuk ayah anda almarhum Bung Karno pernah berkata, "orang cerdik akan cepat tanggap pada situasi”, saya ulangi lagi "orang cerdik akan cepat tanggap pada situasi".)

Dari seluruh kutipan orasi di atas apabila dicermati akan nampak sebuah pesan yaitu "pertikaian akan merugikan diri sendiri dan orang lain".

\section{e. Adegan Pagombakan}

Pada adegan Pagombakan ini terdapat pembicaraan antara Yamawidura dan Kunthi. Dalam dialog tersebut Kunthi berterimakasih karena Yamawidura bersedia menampung Kunthi dan Pandawa. Sebaliknya Yamawidura menyampaikan 


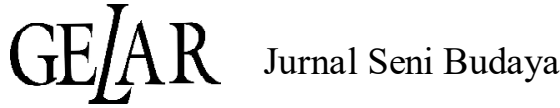

bahwa tindakannya itu belum seberapa jika dibandingkan dengan kebaikan almarhum Prabu Pandu semasa hidup kepadanya. Baik Yamawidura, Kunthi, maupun Pandawa adalah gambaran dari manusia yang selalu mengingat kebaikan orang lain yang pernah diterima. Ginem di atas mengandung pesan bahwa "manusia yang baik akan selalu mengingat kebaikan orang lain sebagai sebuah hutang budi".

Pada saat Yamawidura menyampaikan titah Dhestarastra, Bratasena, Premadi, Nakula dan Sadewa meragukan niat baik Dhestarastra tersebut karena terbukti Kurawa berkali-kali mencoba membunuh para Pandawa, namun Puntadewa justru mempunyai pandapat bahwa seorang kesatria harus menjaga martabat raja dan negaranya walau apapun resikonya. Pesan dari ginem di atas adalah "berbakti kepada negara adalah sikap yang mulia walau sebesar apapun resikonya".

Menanggapi perdebatan di antara anakanaknya, Kunthi mengingatkan para Pandawa bahwa niat baik Dhestarastra harus diterima dengan baik pula, dan malang atau mujurnya nasib manusia itu ditentukan oleh takdir. Kunthi juga menekankan bahwa orang yang selalu menjunjung tinggi kebenaran pasti akan selalu mendapatkan keselamatan. Nasehat Kunthi kepada para Pandawa tersebut mencerminkan suatu keyakinan yang mendalam bahwa nasib manusia itu tidak ditentukan oleh manusia itu sendiri, melainkan ditentukan oleh Tuhan melalui takdir masing-masing manusia. Pesan dari ginem di atas adalah "manusia hanya berusaha, tapi Tuhan yang akan menentukan nasib manusia".

\section{f. Adegan Bratayuda Jayabinangun}

Adegan selanjutnya adalah perang besar antara Pandawa dan Kurawa yang dikenal dengan nama Baratayuda Jayabinangun. Banyak prajurit dan senopati yang gugur dari kedua belah pihak. Yang menarik dari beberapa peristiwa gugurnya para senopati adalah adanya kemiripan, yaitu akibat dari perbuatan masa lalu (karma) mereka. Pesan yang terdapat dalam peristiwa tersebut adalah "setiap manusia pasti akan mempertanggungjawabkan semua perbuatannya".

Perang besar bernama Baratayuda Jayabinangun pun akhirnya selesai dengan kemenangan di pihak Pandawa. Artinya hasil akhir dari Baratayuda sebenarnya mengandung pesan bahwa "kebaikan pasti menang melawan kejahatan".

\section{g. Adegan Hastina}

Setelah Pandawa memenangkan Baratayuda Jayabinangun, para Pandawa datang ke negara Hastina. Kedatangan para Pandawa tersebut disambut oleh Dhestarastra dan Gendari. Dalam peristiwa itu Werkudara menghujat Dhestarastra. Berikut ini kutipan dari ginem tersebut:

Dhestarastra: Werkudara, kok kaya ngono ucapmu dene ora ngajeni wong tuwa.

(Werkudara, kok seperti itu ucapmu tidak menghargai orang tua.)

Sena : Diajeni ora iku, ora marga wong tuwa, nanging saka patrapmu.

(Dihargai atau tidak, itu bukan karena usia, tetapi karena tingkah lakumu.)

Walaupun kata-kata Werkudara di atas sangat kasar, namun mengandung pesan yang sangat berarti, yaitu "manusia dihargai sesuai tingkah lakunya".

Werkudara juga mengecam Dhestarastra karena Dhestarastra dianggap tidak berhasil mendidik anak, bahkan Dhestarastra selalu melindungi perbuatan para Kurawa yang tidak terpuji. Didikan orangtua kepada anak akan sangat berpengaruh pada pembentukan karakter anak tersebut. Artinya karakter buruk dari seorang anak secara tidak langsung juga mencerminkan kegagalan orangtua dalam mendidik anak. Pesan di balik dialog di atas adalah "orangtua berperan besar dalam pembentukan karakter anak".

\section{h. Adegan Dhestarastra dan Gendari}

Pada adegan akhir ditampilkan pertengkaran antara Dhestarastra dan Gendari. Destarastra menganggap bahwa penyebab semua permasalahan tersebut adalah karena bujuk rayu Gendari dan tipu muslihat Sengkuni. Mendengar perkataan Destarastra itu Gendari menyanggah dengan alasan bahwa jika Destarastra adalah orang yang teguh pendiriannya, pasti tidak akan mudah terkena bujuk rayu. Dialog yang berisi pertengkaran Dhestarastra dan Gendari di atas mengandung pesan "orang yang tidak teguh pada pendirian, akan mudah mendapatkan hasutan dan dipengaruhi oleh orang lain". 


\section{Nilai-nilai dalam Lakon Kalabendu}

Setelah mencermati pesan-pesan yang terkandung dalam adegan-adegan pada lakon Kalabendu tersebut, penulis mencari nilai-nilai yang terkandung dalam pesan-pesan tersebut, kemudian mengelompokkannya dalam nilai-nilai sebagai berikut: (1) nilai rendah-hati, (2) nilai kesederhanaan, (3) nilai tanggung-jawab, (4) nilai kejujuran, (5) nilai kebenaran, (6) nilai persatuan, (7) nilai balas budi, (8) nilai ketuhanan, (9) nilai ngundhuh wohing pakarti (hukum karma), (10) nilai pendidikan, dan (11) nilai keteguhan hati.

\section{a. Nilai Rendah-hati}

Rendah hati adalah kebalikan dari sikap sombong. Nilai kerendah-hatian menurut penulis adalah perwujudan dari pemikiran Jawa yang selalu mengajarkan agar manusia berlaku andhap-asor, yaitu sebuah perilaku yang tidak merasa lebih dari orang lain, bahkan selalu bersikap merendah. Nilai Rendahhati ini terlihat dalam adegan prolog yang menyampaikan pesan mengenai "akibat buruk dari kesombongan". Kematian Pandu berawal dari kesombongannya sendiri, ini merupakan contoh dari akibat buruk yang disebabkan karena perilaku sombong. Oleh karena itu jika seseorang selalu bersikap rendah-hati, maka ia akan terhindar dari bahaya-bahaya yang bisa ditimbulkan oleh sikap sombong.

\section{b. Nilai Kesederhanaan}

Hidup dalam kesederhanaan tidak berarti serba terbatas atau miskin. Sederhana adalah sikap hidup yang bagaimana mestinya, sesuai dengan porsinya, dan tidak berlebihan. Nilai kesederhanaan ini bisa dilihat pada adegan Sengkuni dan Gendari yang mengandung pesan "orang yang terlalu larut dalam kenikmatan duniawi, akan mudah mendapatkan celaka". Jika saja Dhestarastra selalu bersikap sederhana dalam gaya hidupnya, maka ia tidak akan mudah dicelakakan oleh Sengkuni dan Gendari.

\section{c. Nilai Tanggung-jawab}

Setiap manusia dalam kehidupan ini mempunyai tanggung-jawab sesuai dengan kedudukan dan kewajibannya masing-masing. Yang dimaksud dengan sikap tanggung-jawab dalam bahasan ini adalah berbuat sebaik mungkin dalam menjalankan kewajiban dan kemudian siap menerima segala apapun akibat dari dilakukannya kewajiban tersebut. Nilai tanggung-jawab dapat dilihat pada janturan adegan jejer pertama Hastina yang mengandung pesan "pemimpin tidak boleh terlalu percaya dengan laporan bawahannya, namun juga berkewajiban untuk turun langsung memeriksanya".

Dalam adegan jejer pertama Hastina tersebut juga terdapat pesan "melemparkan tanggung-jawab dengan menyalahkan orang lain adalah perbuatan yang tidak terpuji", yang terlihat dari dialog antara Bisma dan Sengkuni. Dalam dialog tersebut Sengkuni menyatakan bahwa menurunnya wibawa negara Hastina disebabkan kegagalan pemerintah di masa pemerintahan Prabu Pandhu. Pernyataan Sengkuni tersebut mendapat kecaman keras dari Bisma. Tindakan Sengkuni tersebut menurut Bisma adalah tindakan orang yang tidak mau bertanggung jawab akan tugasnya.

Nilai Tanggung-jawab juga dapat diamati pada adegan Pagombakan yang mengandung pesan bahwa "berbakti kepada negara adalah sikap yang mulia walau sebesar apapun resikonya". Dialog Puntadewa dan Bratasena pada adegan tersebut menunjukkan tanggung-jawab seorang kesatria. Seorang kesatria bertanggung-jawab untuk menjaga martabat raja dan negaranya walau apapun resikonya.

\section{d. Nilai Kejujuran}

Kejujuran juga bermakna kelurusan hati, yang artinya bersikap apa-adanya, tidak menyembunyikan kebohongan, tidak menipu, dan tidak mengingkari janji. Nilai kejujuran juga sangat sesuai dengan pemikiran Jawa yang menyatakan bahwa prasaja iku panulaking rubeda (kejujuran itu menjauhkan masalah).

Nilai kejujuran dapat ditemukan dalam adegan jejer pertama Hastina, pada dialog Yamawidura, Bisma, dan Dhestarastra yang mengandung pesan "antara ucapan dan perbuatan haruslah selaras dan jangan sampai bertolak belakang". Dalam dialog tersebut Yamawidura mengutarakan pendapat bahwa semua usaha yang dilakukan oleh Dhestarastra tidak mendapat dukungan dari pejabat pemerintahan Hastina karena mereka menganggap Dhestarastra tidak konsisten. Peraturan dan perintah yang diucapkan oleh Dhestarastra bertolak belakang dengan tindakan Dhestarastra sendiri.

Nilai kejujuran juga terdapat dalam adegan yang sama pada dialog Bisma dan Dhestarastra. Peringatan Bisma pada Dhestarastra tersebut mengandung pesan bahwa "orang yang ingkar janji akan menerima akibatnya, tidak hanya berupa dosa ketika sudah meninggal, namun juga pada saat masih hidup". Dalam dialog tersebut Bisma mengingatkan Dhestarastra bahwa seorang raja yang ingkar janji akan menerima dosa. Tidak hanya setelah meninggal namun 


\section{GEEAR Jumal scim Bublya}

juga di saat hidup. Terlebih lagi kalau sudah tidak menjabat, pasti akan dicemooh dan dihujat.

\section{e. Nilai Kebenaran}

Yang dimaksud dengan nilai kebenaran disini adalah semua norma yang bertujuan pada kebaikan; hati (ati) yang baik, ucapan (lathi) yang baik, dan perilaku/tindakan (pakarti) yang baik. Sebuah kebenaran yang ditindakkan akan berakibat kebaikan, sebaliknya sebuah kebenaran yang ditinggalkan akan berakibat keburukan.

Nilai kebenaran dapat dicermati dalam adegan jejer Hastina pada dialog Drona yang di dalamnya terdapat pesan bahwa "sebuah negara yang di dalamnya tidak ada lagi kebaikan dan budi luhur, pasti akan menghadapi kehancuran". Pesan tersebut terlihat pada dialog Drona yang menyatakan bahwa persengketaan dan pertengkaran yang selalu terjadi di Hastina tersebut disebabkan karena di Negara Hastina kebaikan hanya tinggal nama, budi luhur sudah hancur. Para pejabatnya hanya mengejar ambisi hingga lupa diri, melanggar aturan kebaikan, berakibat kehancuran negara.

Nilai-nilai kebenaran juga terlihat pada adegan Baratayuda Jayabinangun. Baratayuda Jayabinangun selesai dengan kemenangan di pihak Pandawa. Artinya hasil akhir dari Baratayuda sebenarnya mengandung pesan bahwa "kebaikan pasti menang melawan kejahatan". Pandawa adalah simbol dari manusia yang menjunjung tinggi kebenaran dengan selalu berbuat kebaikan, sedangkan Kurawa adalah simbol dari manusia yang selalu berbuat kejahatan.

\section{f. Nilai Persatuan}

Persatuan adalah sebuah nilai luhur yang mengacu pada kerukunan, kebersamaan, dan kegotong-royongan. Di dalam sebuah persatuan yang dilandasi kerukunan, kebersamaan, dan kegotongroyongan, akan tercipta sebuah kekuatan yang besar yang akan mendorong terwujudnya sebuah cita-cita yang luhur.

Nilai persatuan dapat ditemukan pada adegan limbukan dalam orasi budaya yang mengandung pesan "pertikaian akan merugikan diri sendiri dan orang lain". Dalam orasi tersebut disampaikan kritikan kepada para politikus yang sedang bertikai, agar mereka sadar dan kemudian mau menghilangkan rasa perselisihan dan kembali bersatu dalam landasan kerukunan, kebersamaan, dan kegotong-royongan untuk kemudian bersama-sama membangun bangsa menuju bangsa yang adil, makmur, dan sejahtera.

\section{g. Nilai Balas Budi}

Manusia dalam menjalani hidupnya tidak jarang harus menerima kebaikan/jasa dari manusia lainnya, keadaan tersebut bisa dikatakan sebagai sebuah hutang budi. Setiap manusia yang mempunyai hutang budi berkewajiban untuk membalas budi dari kebaikan/jasa tersebut.

Nilai balas budi dalam lakon Kalabendu terlihat pada adegan Pagombakan. Dalam adegan tersebut terdapat pesan bahwa "manusia yang baik akan selalu mengingat kebaikan orang lain sebagai sebuah hutang budi". Pada ginem antara Yamawidura, Kunti dan Pandawa terlihat bahwa Kunthi dan Pandawa sangat berterimakasih pada kebaikan Yamawidura, namun Yamawidura menyatakan bahwa kebaikannya tersebut belumlah seimbang dengan kebaikan almarhum Pandu kepadanya. Baik Yamawidura, Kunthi, maupun Pandawa adalah gambaran dari manusia yang selalu mengingat kebaikan orang lain yang pernah diterima.

\section{h. Nilai Ketuhanan}

Nilai ketuhanan dalam tulisan ini lebih terfokus pada keyakinan adanya Tuhan, keyakinan akan kuasa Tuhan, dan keyakinan akan adanya takdir Tuhan.

Nilai ketuhanan dapat ditemukan dalam adegan Pagombakan yang memuat pesan bahwa "manusia hanya berusaha, tapi Tuhan yang akan menentukan nasib manusia". Nasehat Kunthi kepada para Pandawa pada adegan tersebut mencerminkan suatu keyakinan yang mendalam bahwa nasib manusia itu tidak ditentukan oleh manusia itu sendiri, melainkan ditentukan oleh Tuhan melalui takdir masing-masing manusia.

\section{i. Nilai Ngundhuh Wohing Pakarti (Hukum Karma)}

Pada dasarnya manusia akan memetik buah perbuatannya (ngundhuh wohing pakarti). Barang siapa menanam kebaikan, ia akan merasakan kebaikan, sebaliknya barang siapa menanam kejelekan mau tidak mau ia juga akan menerima kejelekan dari perbuatannya tersebut (Sarwanto, 2008:329). Peristiwa sebab akibat tersebut juga dikenal dengan nama hukum karma.

Nilai ngundhuh wohing pakarti dapat dilihat dalam adegan Baratayuda Jayabinangun yang menyiratkan pesan bahwa "setiap manusia pasti akan mempertanggungjawabkan semua perbuatannya". Peristiwa-peristiwa gugurnya para senopati dalam Baratayuda. Para senopati tersebut gugur sebagai akibat dari perbuatan masa lalu (karma) mereka. Kematian Bisma di tangan Srikandhi, gugurnya Gatotkaca oleh Karna, kematian Drona oleh 
Drestajumena, gugurnya Salya oleh Puntadewa, tidak lepas dari campur tangan karma.

Adegan lain yang memuat nilai ngundhuh wohing pakarti adalah adegan Hastina setelah Baratayuda Jayabinangun. Dalam adegan itu terdapat dialog Werkudara yang mencemooh dan tidak mau menghormati Dhestarastra karena tingkah laku Dhestarastra yang buruk. Pada dialog tersebut terdapat pesan yang sangat berarti, yaitu "manusia dihargai sesuai tingkah lakunya". Dalam dialog tersebut terlihat bahwa Dhestarastra tidak dihargai dan dihormati oleh keponakannya sendiri karena perbuatan Dhestarastra yang tidak baik di masa lalu.

\section{j. Nilai Pendidikan}

Pendidikan adalah proses belajar yang bertujuan mengembangkan potensi diri baik secara fisik maupun mental untuk berkembang menjadi lebih baik. Pendidikan dapat diperoleh di mana saja, baik itu dalam keluarga, sekolah, maupun lingkungan. Semenjak kanak-kanak hingga dewasa, manusia mengalami proses pendidikan selama hidupnya, yang pada akhirnya akan mempengaruhi kemampuan dan karakter manusia.

Nilai pendidikan dapat ditemukan dalam adegan Hastina setelah Bratayuda, pada dialog Werkudara dan Dhestarastra yang mengandung pesan "orang tua berperan besar dalam pembentukan karakter anak". Dalam dialog tersebut Werkudara menganggap Dhestarastra tidak berhasil mendidik anak, bahkan Dhestarastra selalu melindungi perbuatan para Kurawa yang tidak terpuji. Pendidikan dari orang tua kepada anak akan sangat berpengaruh pada pembentukan karakter anak tersebut. Artinya karakter buruk dari seorang anak secara tidak langsung juga mencerminkan kegagalan orang tua dalam mendidik anak.

\section{k. Nilai Keteguhan Hati}

Ketika manusia telah mengetahui dan meyakini sebuah kebenaran, manusia tersebut harus menjaga keyakinannya itu dari keragu-raguan yang dapat mengakibatkan berubahnya keyakinannya akan kebenaran tersebut. Sikap itulah yang merupakan perwujudan dari nilai keteguhan hati.

Nilai keteguhan hati dapat dijumpai pada adegan akhir yaitu dialog antara Gendari dan Dhestarastra. Pada dialog yang berisi pertengkaran Dhestarastra dan Gendari tersebut mengandung pesan "orang yang tidak teguh pada pendirian, akan mudah mendapatkan hasutan dan dipengaruhi oleh orang lain".

\section{E. Kesimpulan}

Struktur dramatik lakon Kalabendu susunan Sumanto sajian Manteb Soedharsono ini sebenarnya merupakan petikan adegan-adegan penting dari beberapa lakon tradisi yaitu : (1) lakon Pamuksa (pertempuran antara Pandu dan Tremboko); (2) lakon Bale Sigala-gala (usaha Kurawa untuk membunuh Pandawa dengan cara membuat perangkap untuk membakar Pandawa hidup-hidup di dalam Bale Sigalagala); (3) lakon Bratayuda (cerita peperangan Pandawa melawan Kurawa yang berakhir dengan kemenangan Pandawa); dan (4) lakon Pendhawa Boyong (cerita setelah perang Baratayuda berakhir dan Pandawa menempati kerajaan Hastina).

Tahapan-tahapan dramatik lakon Kalabendu susunan Sumanto sajian Manteb Soedharsono sebagai berikut:

a) Tahap exposition yaitu dimulai sejak adegan peperangan antara Prabu Pandhu melawan Prabu Tremboko, adegan amanat Pandu pada Destarastra, hingga adegan Gendari dan Sengkuni yang berencana untuk menguasai Negara Hastina.

b) Tahap inciting-action yaitu berisi adegan persidangan Hastina lima tahun semenjak kematian Pandhu.

c) Tahap conflication yaitu adegan Pagombakan, adegan Pandawa menempati Pura Waranawata, hingga adegan Purucana membakar Pura Waranawata.

d) Tahap crisis yaitu terdapat pada adegan penobatan Kurupati menjadi raja Hastina.

e) Tahapan climax yaitu terdapat pada adegan Baratayuda.

f) Tahap resolution yaitu pada saat kedatangan para Pandawa ke Hastina.

g) Tahap conclucion yaitu pada adegan Destarastra dan Gendari meratapi nasib mereka yang sengsara.

Dalam sanggit catur lakon Kalabendu susunan Sumanto terdapat sanggit janturan (janturan jejer, janturan adegan, dan janturan peristiwa), sanggit pocapan (pocapan situasi, pocapan peristiwa, pocapan mandiri, dan pocapan peralihan), serta sanggit ginem (ginem blangkon, ginem baku, ginem isen-isen, dan ginem banyol). Adapun dalam garap catur lakon Kalabendu sajian Manteb Soedharsono terdapat garap janturan (janturan adegan), garap pocapan (pocapan peristiwa), dan garap ginem (ginem blangkon).

Nilai-nilai yang disampaikan dalam lakon Kalabendu susunan Sumanto sajian Manteb 


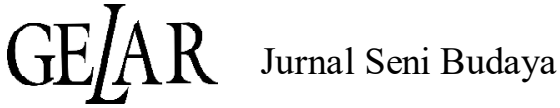

Soedharsono adalah: nilai rendah-hati, nilai kesederhanaan, nilai tanggung-jawab, nilai kejujuran, nilai kebenaran, nilai persatuan, nilai balas budi, nilai ketuhanan, nilai ngundhuh wohing pakarti (hukum karma), nilai pendidikan, dan nilai keteguhan hati.

\section{KEPUSTAKAAN}

Murtiyoso, B., Sumanto, Suyanto, Kuwato. Teori Pedalangan, Bunga Rampai ElemenElemen Dasar Pakeliran. ISI Surakarta dan Percetakan CV Saka Production Surakarta, 2007.

Nugroho, Sugeng. "Sanggit dan Garap Lakon Banjaran Pertunjukan Wayang Kulit Purwa Gaya Surakarta". Disertasi S3 Sekolah Pascasarjana Universitas Gadjah Mada Yogyakarta, 2012.
Saptaria, Rikrik El. Acting Handbook : Panduan Praktis Akting untuk Film \& Teater. Bandung: Rekayasa Sains, 2006.

Sarwanto, Pertunjukan Wayang Kulit Purwa dalam Ritual Bersih Desa Kajian Fungsi dan Makna. Surakarta: Kerjasama antara Pascasarjana, ISI Press, dan CV Cendrawasih, 2008.

Subono, Blacius. "Lakon Kalabendu di Mata Seorang Pengamat Wayang," LAKON, Jurnal Jurusan Pedalangan ISI Surakarta, Volume IV No. 1 (Juli 2007): 89-96.

Suratno. "Makna dan Fungsi Pertunjukan wayang Kulit pada Upacara Ritual di Dukuh Logantung, Semin, Gunung Kidul," Dewa Ruci, Jurnal Pengkajian dan Penciptaan Seni, Vol 4. No 3. 357-373. 